\title{
Methacholine bronchial provocation test for assessment of bronchial hyperresponsiveness in preschool children
}

\author{
Bao-Hong Li ${ }^{1,2 \#}$, Wei-Jie Guan ${ }^{1 \#}$, Zheng Zhu ${ }^{1,3 \#}$, Yi Gao ${ }^{1}$, Jia-Ying An ${ }^{1}$, Xin-Xin Yu ${ }^{1}$, Jin-Ping Zheng ${ }^{1}$ \\ ${ }^{1}$ State Key Laboratory of Respiratory Diseases, National Clinical Research Center of Respiratory Disease, The First Affiliated Hospital of \\ Guangzhou Medical University, Guangzhou Institute of Respiratory Health, Guangzhou 510120, China; ${ }^{2}$ People's Hospital of Liwan District, \\ Guangzhou, Guangzhou 510120, China; ${ }^{3}$ Department of Allergy and Clinical Immunology, State Key Laboratory of Respiratory Diseases, \\ Guangzhou Institute of Respiratory Health, The First Affiliated Hospital of Guangzhou Medical University, Guangzhou 510120, China \\ Contributions: (I) Conception and design: JP Zheng, BH Li, Y Gao; (II) Administrative support: JP Zheng; (III) Provision of study materials or \\ patients: JP Zheng; (IV) Collection and assembly of data: WJ Guan, Z Zhu, BH Li, Y Gao; (V) Data analysis and interpretation: WJ Guan, Z Zhu, \\ BH Li, Y Gao; (VI) Manuscript writing: All authors; (VII) Final approval of manuscript: All authors. \\ "These authors shared co-first authorship. \\ Correspondence to: Jin-Ping Zheng, MD. State Key Laboratory of Respiratory Disease, National Clinical Research Center of Respiratory Disease, \\ Guangzhou Institute of Respiratory Health, The First Affiliated Hospital of Guangzhou Medical University, 151 Yanjiang Road, Guangzhou 510120 , \\ China. Email: jpzhenggy@163.com.
}

Background: Bronchial hyperresponsiveness (BHR) has not been extensively performed in preschool children, possibly because of the difficulty in cooperating with the tests. We sought to determine the usefulness and safety of methacholine bronchial provocation test (MCh-BPT) for BHR assessment in preschool children.

Methods: We recruited 252 preschool children (190 healthy and 62 with wheezing) who underwent MChBPT at baseline. MCh-BPT was re-scheduled in case initial attempts failed. Forced expiratory volumes in 0.5 $\left(\mathrm{FEV}_{0.5}\right), 0.75\left(\mathrm{FEV}_{0.75}\right)$ and one second $\left(\mathrm{FEV}_{1}\right)$ were measured. We recorded the provocative dose causing $15 \%\left(\mathrm{PD}_{15}\right)$ or $20 \%$ reduction $\left(\mathrm{PD}_{20}\right)$ in $\mathrm{FEV}_{0.5}, \mathrm{FEV}_{0.75}$ and $\mathrm{FEV}_{1}$, thus allowing for comparison of the diagnostic value of $\mathrm{PD}_{15}$ and $\mathrm{PD}_{20}$.

Results: A total of 209 children [156 (82.1\%) healthy, 53 (85.5\%) with wheezing] successfully completed MCh-BPT. Compared with healthy children, a significantly greater proportion of children with wheezing had measurable $\mathrm{PD}_{15} \mathrm{FEV}_{0.5}, \mathrm{PD}_{15} \mathrm{FEV}_{0.75}$ and $\mathrm{PD}_{15} \mathrm{FEV}_{1}(\mathrm{P}<0.01)$, and $\mathrm{PD}_{20} \mathrm{FEV}_{0.5}, \mathrm{PD}_{20} \mathrm{FEV}_{0.75}$ and $\mathrm{PD}_{20} \mathrm{FEV}_{1}(\mathrm{P}<0.05)$. The sensitivity was $92.5 \%$ and $94.3 \%$ for $\mathrm{PD}_{20} \mathrm{FEV}_{1}$, and $\mathrm{PD}_{15} \mathrm{FEV}_{1}$ and the specificity was $93.6 \%$ and $93.6 \%$ respectively, for discriminating asthmatic from healthy children.

Conclusions: Most preschool children successfully and safely complete MCh-BPT, with higher success rate in larger age group. $\mathrm{PD}_{20} \mathrm{FEV}_{0.5}$ and $\mathrm{PD}_{20} \mathrm{FEV}_{0.75}$ can be surrogates of $\mathrm{PD}_{20} \mathrm{FEV}_{1}$ among children whose expiration lasted for less than one second. $\mathrm{PD}_{15}$ has a good diagnostic value as $\mathrm{PD}_{20}$ for diagnosing of $\mathrm{BHR}$ in preschool children, which are also more suitable for children five years old or elder.

Keywords: Preschool children; bronchial hyperresponsiveness (BHR); bronchial provocation test; methacholine; safety

Submitted Apr 09, 2019. Accepted for publication Sep 13, 2019.

doi: $10.21037 /$ jtd.2019.09.47

View this article at: http://dx.doi.org/10.21037/jtd.2019.09.47

\section{Introduction}

Asthma is a chronic airway inflammation disease resulting from interactions among genetic factors, environmental pollution, and allergen sensitization (1-3). The prevalence of asthma is estimated to be 300 million globally (1) and still increasing $(1,2)$. There has been a rapid increase in the 
prevalence of asthma among children in China, possibly because of severe air pollution, and altered environmental exposures and dietary patterns (2-5). The cumulative prevalence of asthma in children under 14 years of age has increased from $1.90 \%$ in 1990 (4) and $1.09 \%$ in 2000 (5) to $3.02 \%$ in 2010 (6). Moreover, approximately $30 \%$ of asthmatic children have been underdiagnosed in urban areas of China $(5,6)$. In clinical, the diagnosis of asthma relies heavily on clinical history, however, the measurement of bronchial hyperresponsiveness (BHR), a cardinal pathophysiologic feature (7), with practical approaches such as bronchial provocation test (BPT) (8), is helpful for the diagnosis and differential diagnosis of asthma, especially for those with uncertain history.

Forced expiratory volume in one second $\left(\mathrm{FEV}_{1}\right)$ has been the "gold standard" for determining BHR in children aged five years or greater (1). Nevertheless, BPT with spirometry may be challenging among preschool children because of their developmental characteristics (limited ability to comprehend and cooperate), which reduced the reliability of results. Understanding the feasibility of BPT in preschool children (with uncertain history, particularly those with chronic cough and wheezing) may be of practical value (e.g., for differential diagnosis of asthma) (9). Despite the publication of European Respiratory Society/American Thoracic Society recommendations of spirometry (7), no guidelines for BPT specifically targeting at preschool children have been drafted.

We hypothesized that methacholine bronchial provocation test (MCh-BPT) would be safe and feasible in preschool children. To this end, we conducted MCh-BPT in healthy children and preschool children who previously had wheezing, we also evaluated the optimal parameter for determining the positive response for diagnosing BHR.

\section{Methods}

\section{Subjects}

Children aged 4-6 years were recruited from a kindergarten located in Guangzhou and the pediatric outpatient department of The First Affiliated Hospital of Guangzhou Medical University. All subjects were categorized into healthy children or wheezing children, according to the history of recurrent wheezing. All subjects had normal height and weight ( \pm 2 standard deviations) (10), had no history of other severe cardiopulmonary diseases, and had no acute airway infection within 4 weeks. Healthy children had no recurrent wheezing diseases, no prior exposure to noxious gases or dust; had normal chest physical examination findings. Children with wheezing had either a history two or more episodes of wheezing (without upper or lower airway infection), or a clinical diagnosis of asthma $(1,11)$. We excluded subjects with baseline $\mathrm{FEV}_{1}$ $<60 \%$ predicted, and those who failed to complete MChBPT. Subjects that under allergen immunology were also excluded. Inhaled short-acting and long-acting $\beta 2$ receptor agonist were withheld for at least 8 and 24 hours respectively, before any bronchial challenge test. Antihistamines and leukotrienes receptor antagonists were withheld for at least 3 days prior to the study.

The study protocol was approved by the ethics committee of The First Affiliated Hospital of Guangzhou Medical University, and parents signed informed consent.

\section{Spirometry}

Spirometry was performed with MasterScope spirometer (Carefusion Co. Ltd., Hoechberg, Germany) by experienced technicians according to international guidelines (7). Baseline spirometry was performed for 3-8 times (at 1-min intervals) to obtain at least two technically acceptable curves. Reference values were derived from the equation by Zhang et al. (12).

\section{$M C b-B P T$}

MCh-BPT with doubling (for children with wheezing) and quadrupling (for healthy children) provocative concentrations of methacholine was performed with Masterscreen system (DeVilbiss 646 nebulizer, power: $160 \mu \mathrm{L} / \mathrm{min}$, Carefusion Co. Ltd., Hoechberg, Germany) by using Yan's and Zhong's approach of deep inhalation $(13,14)$. The initial and final dose of MCh (Sigma-Aldrich Co, St Louis, Mo) was 0.39 and $12.80 \mu \mathrm{mol}$, respectively (Table S1). Repeated inhalation challenges were performed at 1-minute intervals. These procedures were terminated when $\mathrm{FEV}_{1}$ reduced by $20 \%$ or the final dosing was accomplished (Figure S1). 200-400 mcg salbutamol was administered via a spacer (Volumatic, Allen \& Hanbury's, UK) to relieve discomfort among subjects whose $\mathrm{FEV}_{1}$ fall exceeded $20 \%$. The cumulative doses of MCh causing $\mathrm{FEV}_{0.5}, \mathrm{FEV}_{0.75}$ and $\mathrm{FEV}_{1}$ to decrease by $15 \%\left(\mathrm{PD}_{15} \mathrm{FEV}_{0.5}\right.$, $\left.\mathrm{PD}_{15} \mathrm{FEV}_{0.75}, \mathrm{PD}_{15} \mathrm{FEV}_{1}\right)$ and $20 \%\left(\mathrm{PD}_{20} \mathrm{FEV}_{0.5}, \mathrm{PD}_{20} \mathrm{FEV}_{0.75}\right.$ and $\mathrm{PD}_{20} \mathrm{FEV}_{1}$ ), causing peak expiratory flow (PEF) to decrease by $20 \%\left(\mathrm{PD}_{20} \mathrm{PEF}\right)$, and causing maximal mid- 


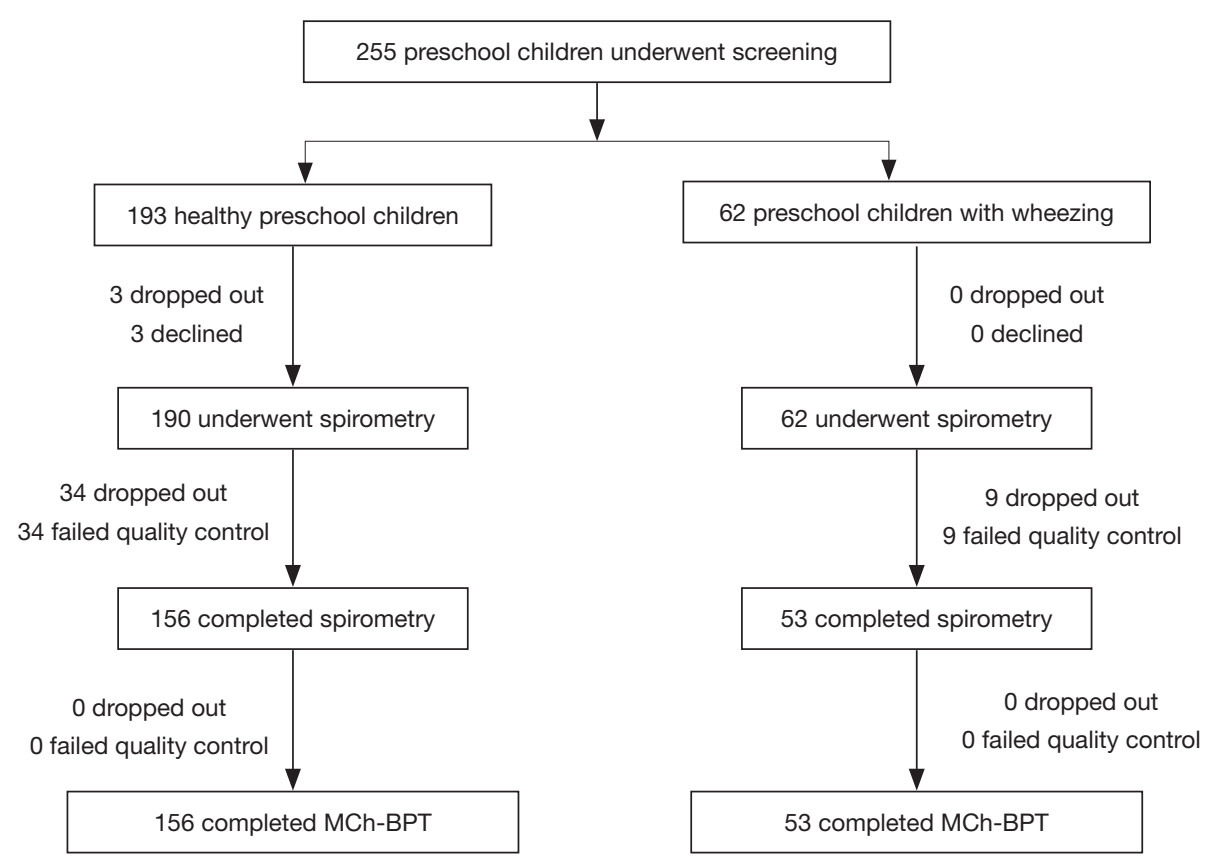

Figure 1 Subject enrollment. Mch-BPT, methacholine bronchial provocation test.

expiratory flow (MMEF) to decrease by $35 \%$ ( $\mathrm{PD}_{35} \mathrm{MMEF}$ ) were calculated.

For children with wheezing, failure of test was defined as inability to complete spirometry. MCh-BPT would be rescheduled one week thereafter in case the initial MChBPT (but not spirometry) was unsuccessful. No further attempts were made in case two consecutive MCh-BPT could not be completed successfully. For healthy children who tested positive to the initial MCh-BPT, they were invited for repeated MCh-BPT at one-month interval. BHR could be confirmed among healthy children who tested positive ( $\mathrm{FEV}_{1}$ fall exceeded $20 \%$ ) on both occasions. However, among children with wheezing, BHR was diagnosed if they tested positive at either occasion.

\section{Statistical analysis}

Statistical analysis was performed by using the SPSS 16.0 software package (SPSS Inc., Chicago, Illinois, USA). Data were expressed as mean \pm standard deviation for normal distribution or otherwise median (interquartile range) for non-normal distribution. Independent $t$-test or Mann-Whitney $U$ test was used to compare the difference between the two groups. The chi-square test was used to compare the categorical variables. $\mathrm{P}<0.05$ was considered as statistically significant.

\section{Results}

\section{Baseline characteristics}

A total of 252 (190 healthy and 62 wheezing) children aged 4-6 years were enrolled. The recruitment flow chart is shown in Figure 1. There is no significantly different of height and weight between healthy children and those with wheezing $(\mathrm{P}>0.05)$. The demographic characteristics and history of atopy are shown in Table 1.

\section{Success rate of spirometry}

The success rate of performing spirometry in healthy children was $73.2 \%(139 / 190)$ for the initial visit and $82.1 \%$ $(156 / 190)$ for two visits. The success rate of the 4-yearold group was significantly lower than that of 5 -year-old group and 6-year-old group $(68.0 \%$ vs. $86.7 \%$ vs. $96.4 \%$, both $\mathrm{P}<0.05)$. The mean duration of expiration in healthy children was $1.74 \mathrm{~s}$, with seven $(4.5 \%)$ children whose expiration lasted for no more than one second. In children 
Table 1 Characteristics in different age groups

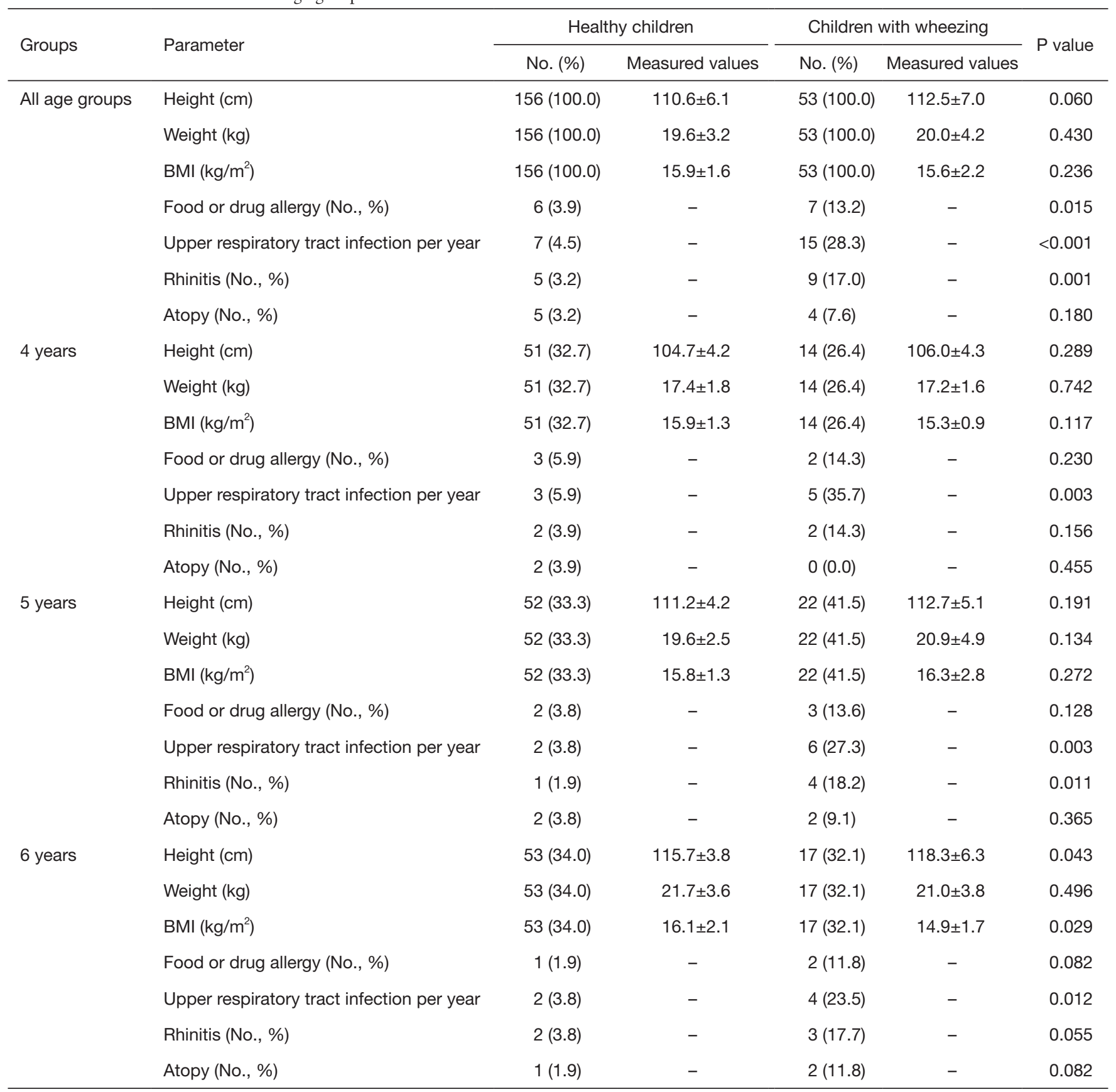

The data are shown as mean \pm standard deviation for normal distribution or median (interquartile range) for non-normal distribution. The percentages were calculated based on the number of different ages groups of healthy children and wheezing children.

with wheezing, the success rate of spirometry and MChBPT was $85.5 \%(73.7 \%$ vs. $88.0 \%$ vs. $94.4 \%$ in $4-$, 5 and 6-year-old groups, respectively), without significant differences between healthy and wheezing groups $(\mathrm{P}>0.05)$ (Table 2).

\section{Comparison of $B H R$}

Of the 156 healthy children who successfully performed spirometry and MCh-BPT, 11 had an $\mathrm{FEV}_{1}$ decrease for greater than $20 \%$ during the initial visit. At reassessment one month thereafter, 10 children $(6.4 \%)$ had an $\mathrm{FEV}_{1}$ 
Table 2 Rate of children who successfully completed spirometry and MCh-BPT in different age groups

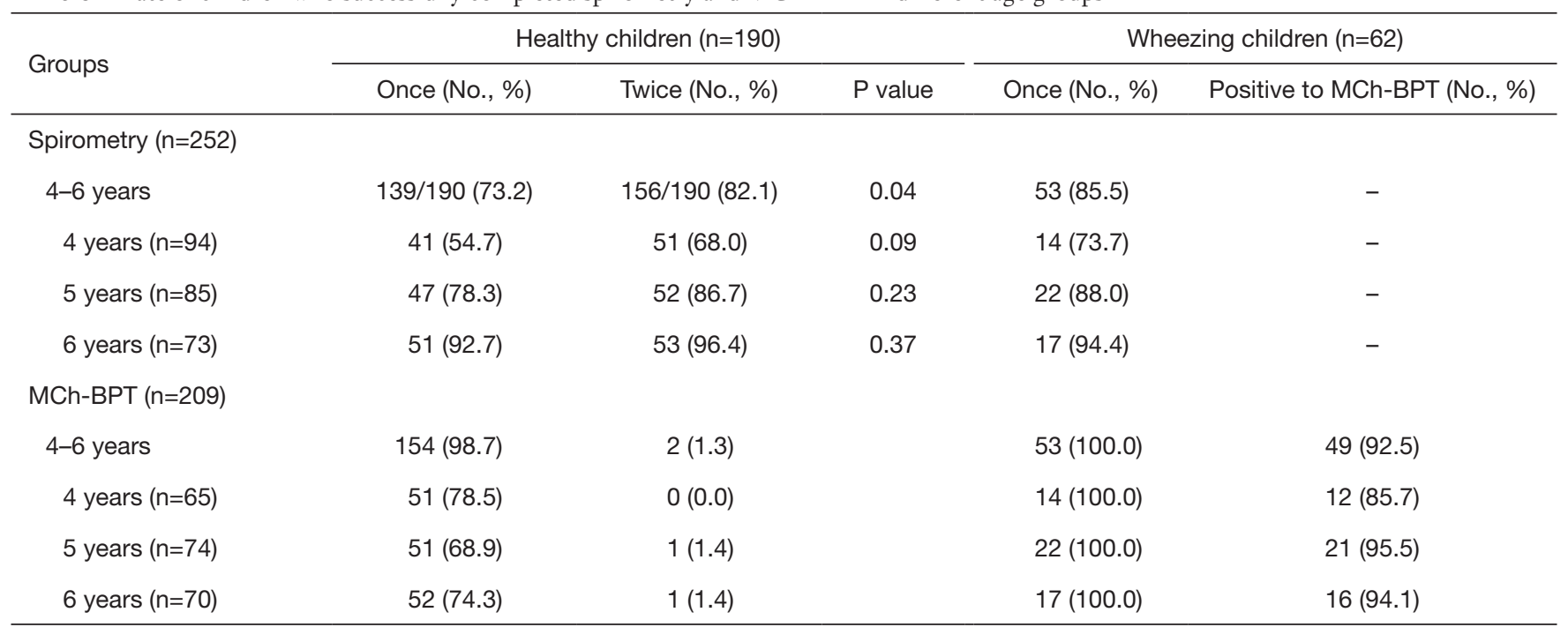

The percentages were calculated based on the number of different ages groups of healthy children and wheezing children. Mch-BPT, methacholine bronchial provocation test.

Table 3 Diagnostic values of $\mathrm{FEV}_{0.5}, \mathrm{FEV}_{0.75}$, PEF, and MMEF, according to $\mathrm{FEV}_{1}$

\begin{tabular}{|c|c|c|c|c|c|c|c|c|c|}
\hline \multirow{2}{*}{ Parameter } & \multicolumn{2}{|c|}{ Wheezing group $(n=53)$} & \multicolumn{2}{|c|}{ Healthy group $(n=156)$} & \multirow{2}{*}{$\begin{array}{c}\text { Sensitivity } \\
(\%)\end{array}$} & \multirow{2}{*}{$\begin{array}{l}\text { Specificity } \\
(\%)\end{array}$} & \multirow{2}{*}{$\begin{array}{l}\text { Youden } \\
\text { index }\end{array}$} & \multirow{2}{*}{$\begin{array}{c}\text { Positive predictive } \\
\text { value (\%) }\end{array}$} & \multirow{2}{*}{$\begin{array}{c}\text { Negative predictive } \\
\text { value (\%) }\end{array}$} \\
\hline & Positive & Negative & Positive & Negative & & & & & \\
\hline $\mathrm{FEV}_{1}$ & 46 & 7 & 10 & 146 & 86.8 & 93.6 & 0.80 & 82.1 & 97.2 \\
\hline $\mathrm{FEV}_{0.5}$ & 45 & 8 & 10 & 146 & 90.0 & 93.6 & 0.83 & 81.8 & 94.8 \\
\hline $\mathrm{FEV}_{0.75}$ & 45 & 8 & 10 & 146 & 90.0 & 93.6 & 0.83 & 81.8 & 94.8 \\
\hline MMEF & 35 & 18 & 14 & 142 & 66.0 & 91.0 & 0.57 & 71.4 & 88.7 \\
\hline
\end{tabular}

$\mathrm{FEV}_{0.5}$, forced expiratory volumes in $0.5 ; \mathrm{FEV}_{0.75}$, forced expiratory volumes in 0.75 ; $\mathrm{FEV}_{1}$, forced expiratory volumes in one second; PEF, peak expiratory flow; MMEF, causing maximal mid-expiratory flow.

decrease for greater than $20 \%$. There was no significant difference of the values of $\mathrm{PD}_{20} \mathrm{FEV}_{0.5}, \mathrm{PD}_{20} \mathrm{FEV}_{0.75}$ and $\mathrm{PD}_{20} \mathrm{FEV}_{1}$ of the $10 \mathrm{BHR}$ positive children in healthy subject group. Of the 10 children who had an $\mathrm{FEV}_{1}$ decrease for greater than $20 \%$, eight had a history of allergy, frequent upper respiratory tract infection, eczema, allergic rhinitis, and family asthma history.

Of the 53 children with wheezing who had successfully completed spirometry and MCh-BPT, 49 (92.5\%) tested positive to MCh-BPT. The positive rate of MCh-BPT did not differ significantly between different age groups $(85.7 \%$ in 4-year-old group vs. $95.5 \%$ in 5-year-old group vs. $94.1 \%$ in 6-year-old group, $\mathrm{P}>0.05$ ) (Table 2). Although there was no significant difference in the positive rate of $\mathrm{MCh}$ -
BPT [97.4\% (37/38) vs. 80.0\% (12/15), P>0.05], however, with significant lower $\mathrm{PD}_{20} \mathrm{FEV}_{1}$ in children with clinically diagnosed asthma than those with a history of wheezing only children $(4.40 \pm 3.67$ vs. $7.87 \pm 3.78 \mu \mathrm{mol}, \mathrm{P}=0.007)$.

\section{Diagnostic value of different parameters}

Of the 49 children with wheezing that tested positive to MCh-BPT, 46 subjects had both an expiration of more than one second and an $\mathrm{FEV}_{1}$ decrease of greater than $20 \%$. The positive rates of $\mathrm{FEV}_{0.5}, \mathrm{FEV}_{0.75}, \mathrm{PEF}$ and $\mathrm{MMEF}$ are shown in Table 3. Comparison of the provocative doses revealed that both $\mathrm{FEV}_{0.75}$ and $\mathrm{FEV}_{0.5}$, but not PEF and MMEF, could be the surrogates of $\mathrm{FEV}_{1}$ in children with an 
Table 4 Comparison of different cumulative doses of MCh for diagnosing BHR

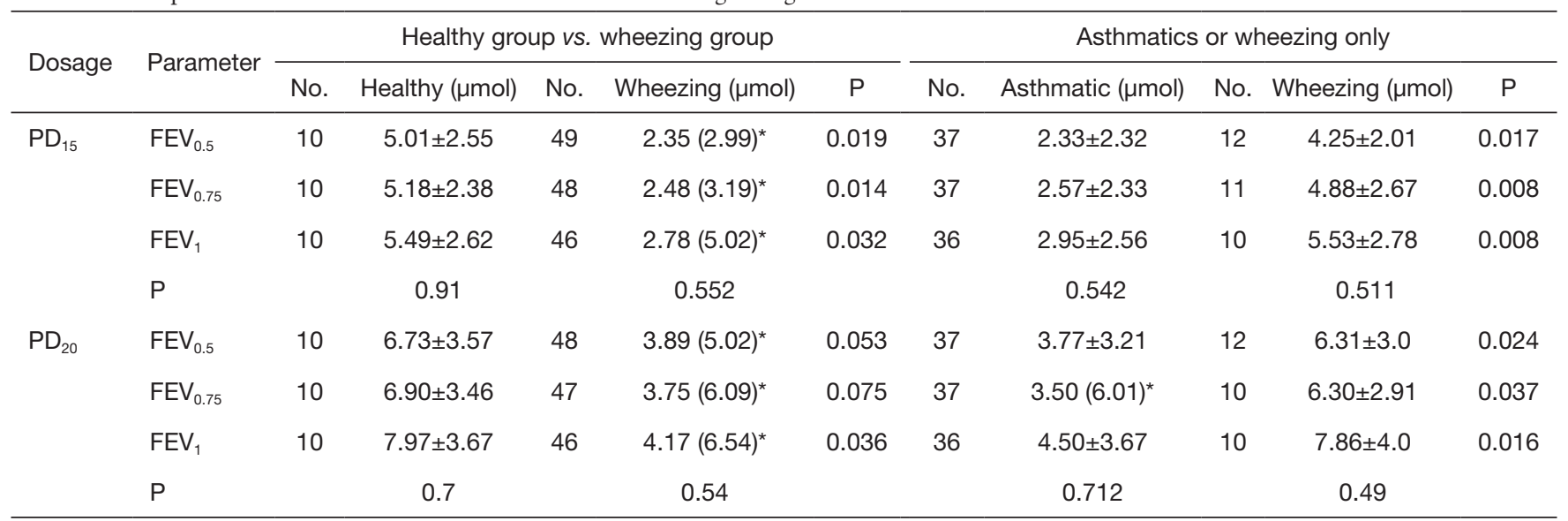

The data are shown as mean \pm standard deviation for normal distribution or median (interquartile range) for non-normal distribution. *, non-normal distribution. $\mathrm{PD}_{15}$, provocative dose causing $15 \%$ reduction in $\mathrm{FEV}_{0.5}, \mathrm{FEV}_{0.75}$ and $\mathrm{FEV}_{1} ; \mathrm{PD}_{20}$, provocative dose causing $20 \%$ reduction in $\mathrm{FEV}_{0.5}, \mathrm{FEV}_{0.75}$ and $\mathrm{FEV}_{1}$. Mch, methacholine; BHR, bronchial hyperresponsiveness; $\mathrm{FEV}_{0.5}$, forced expiratory volumes in 0.5 ; $\mathrm{FEV}_{0.75}$, forced expiratory volumes in $0.75 ; \mathrm{FEV}_{1}$, forced expiratory volumes in one second.
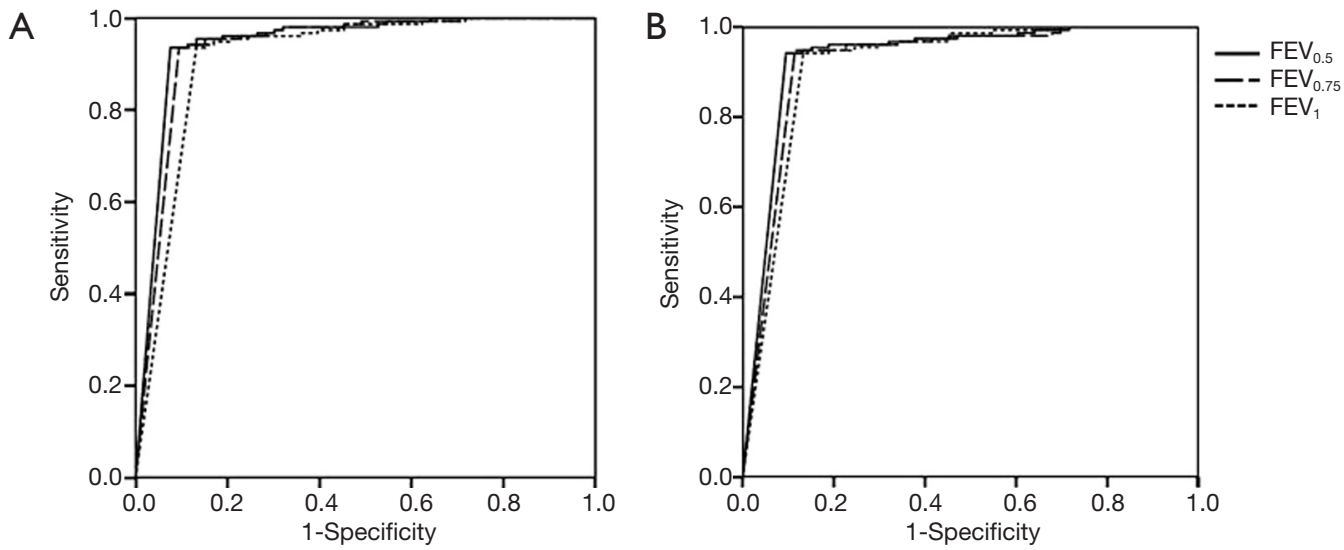

Figure 2 Receive operation characteristic curve of $\mathrm{PD}_{15} \mathrm{FEV}_{0.5}, \mathrm{PD}_{15} \mathrm{FEV}_{0.75}, \mathrm{PD}_{15} \mathrm{FEV}_{1}(\mathrm{~A})$ and $\mathrm{PD}_{20} \mathrm{FEV}_{0.5}, \mathrm{PD}_{20} \mathrm{FEV}_{0.75}$ and $\mathrm{PD}_{20} \mathrm{FEV}_{1}$ (B) for diagnosing asthma. The area under the curve (AUC) of receiver operating characteristic curves $(\mathrm{ROC})$ of $\mathrm{PD}_{15} \mathrm{FEV}_{0.5}, \mathrm{PD}_{15} \mathrm{FEV}_{0.75}$, $\mathrm{PD}_{15} \mathrm{FEV}_{1}$ and $\mathrm{PD}_{20} \mathrm{FEV}_{0.5}, \mathrm{PD}_{20} \mathrm{FEV}_{0.75}$ and $\mathrm{PD}_{20} \mathrm{FEV}_{1}$ were 0.944 (95\% CI: 0.900, 0.988), 0.935 (95\% CI: 0.887, 0.984), 0.914 (95\% CI: $0.858,0.970$ ) and 0.932 (95\% CI: 0.883, 0.981), 0.922 (95\% CI: 0.869, 0.975), 0.914 (95\% CI: 0.858, 0.970), respectively. FEV 0.5 , forced expiratory volumes in $0.5 ; \mathrm{FEV}_{0.75}$, forced expiratory volumes in $0.75 ; \mathrm{FEV}_{1}$, forced expiratory volumes in one second.

expiration of less than one second.

The $\mathrm{PD}_{15} \mathrm{FEV}_{0.5}, \mathrm{PD}_{15} \mathrm{FEV}_{0.75}$ and $\mathrm{PD}_{15} \mathrm{FEV}_{1}$ were significantly lower in children with wheezing than those tested positive to MCh-BPT in healthy children [2.35 (2.99) vs. $5.01 \pm 2.55 \mu \mathrm{mol}$ for $\mathrm{PD}_{15} \mathrm{FEV}_{0.5}, 2.48$ (3.19) vs. $5.18 \pm 2.38 \mu \mathrm{mol}$ for $\mathrm{PD}_{15} \mathrm{FEV}_{0.75}, 2.78$ (5.02) vs. 5.49 $\pm 2.62 \mu \mathrm{mol}$ for $\mathrm{PD}_{15} \mathrm{FEV}_{1}$, all $\mathrm{P}<0.05$, Table 4]. The area under the curve (AUC) of receiver operating characteristic curves (ROC) of $\mathrm{PD}_{15} \mathrm{FEV}_{0.5}, \mathrm{PD}_{15} \mathrm{FEV}_{0.75}, \mathrm{PD}_{15} \mathrm{FEV}_{1}$ and $\mathrm{PD}_{20} \mathrm{FEV}_{0.5}$, $\mathrm{PD}_{20} \mathrm{FEV}_{0.75}$ and $\mathrm{PD}_{20} \mathrm{FEV}_{1}$ for the diagnosis of $\mathrm{BHR}$ was
0.944 (95\% CI: 0.900, 0.988), 0.935 (95\% CI: 0.887, 0.984), 0.914 (95\% CI: $0.858,0.970)$ and 0.932 (95\% CI: 0.883 , 0.981), 0.922 (95\% CI: 0.869, 0.975), 0.914 (95\% CI: 0.858 , 0.970), respectively (Figure 2).

The positive rate of MCh-BPT, determined with $\mathrm{PD}_{20} \mathrm{FEV}_{1}$, was $6.4 \%$ in healthy children and $92.5 \%$ in children with wheezing. $\mathrm{PD}_{20} \mathrm{FEV}_{1}$ in children with wheezing was significantly lower than that of healthy children [4.17 (6.54) vs. 7.97 $\pm 3.67 \mu \mathrm{mol}, \mathrm{P}<0.05]$, whereas $\mathrm{PD}_{20} \mathrm{FEV}_{0.5}[3.89$ (5.02) vs. $6.73 \pm 3.57 \mu \mathrm{mol}, \mathrm{P}>0.05]$ and 
Table 5 Adverse events in different age groups

\begin{tabular}{|c|c|c|c|c|c|c|c|}
\hline Groups & $\begin{array}{c}\text { Mild wheeze } \\
(\%)\end{array}$ & $\begin{array}{l}\text { Pharyngeal } \\
\text { itching (\%) }\end{array}$ & Cough (\%) & Hoarseness (\%) & Sore throat (\%) & $\begin{array}{c}\text { Shortness of } \\
\text { breath (\%) }\end{array}$ & $\begin{array}{c}\text { Chest tightness } \\
(\%)\end{array}$ \\
\hline Healthy children $(n=156)$ & $4(2.6)$ & $7(4.5)$ & $2(1.3)$ & $3(1.9)$ & $1(0.6)$ & $0(0.0)$ & $0(0.0)$ \\
\hline 5 years $(n=52)$ & $1(1.9)$ & $2(3.9)$ & $1(1.9)$ & $1(1.9)$ & $1(1.9)$ & $0(0.0)$ & $0(0.0)$ \\
\hline 6 years $(n=53)$ & $2(3.8)$ & $3(5.7)$ & $0(0.0)$ & $2(3.8)$ & $0(0.0)$ & $0(0.0)$ & $0(0.0)$ \\
\hline 4 years $(n=14)$ & $6(42.9)$ & $2(14.3)$ & $2(14.3)$ & $0(0.0)$ & $0(0.0)$ & $0(0.0)$ & $0(0.0)$ \\
\hline 5 years $(n=22)$ & $9(40.9)$ & $1(4.5)$ & $2(9.1)$ & $0(0.0)$ & $1(4.5)$ & $0(0.0)$ & $1(4.5)$ \\
\hline 6 years $(n=17)$ & $7(41.2)$ & $2(11.8)$ & $3(17.6)$ & $0(0.0)$ & $0(0.0)$ & $0(0.0)$ & $0(0.0)$ \\
\hline
\end{tabular}

$\mathrm{PD}_{20} \mathrm{FEV}_{0.75}[3.75$ (6.09) vs. 6.90 $3.46 \mu \mathrm{mol}, \mathrm{P}>0.05]$ were comparable between the two groups. Among children with wheezing, $\mathrm{PD}_{20} \mathrm{FEV}_{0.5}, \mathrm{PD}_{20} \mathrm{FEV}_{0.75}$ and $\mathrm{PD}_{20} \mathrm{FEV}_{1}$ were significantly lower in children with a clinical diagnosis of asthma than in those who had a history of wheezing but no clinically diagnosed asthma $[3.77 \pm 3.21$ vs. $6.31 \pm 3.0 \mu \mathrm{mol}, 3.50$ (6.01) vs. $6.30 \pm 2.91 \mu \mathrm{mol}, 4.50 \pm 3.67$ vs. $7.86 \pm 4.0 \mu \mathrm{mol}, \mathrm{P}<0.05]$.

\section{Adverse effects}

Adverse events happened during the MCh-BPT included transient wheezing, cough, pharyngeal itching, hoarseness, sore throat, shortness of breath, chest tightness, which were mild and comparable in different age groups (Table 5). Mild wheezing and cough were significantly more common in children with wheezing than in healthy children $(41.5 \%$ vs. $2.6 \%, 13.2 \%$ vs. $1.3 \%, \mathrm{P}<0.01$ ), whereas the incidence of sore throat, hoarseness and chest tightness was comparable between the two groups (all $\mathrm{P}>0.05$ ). After challenge, 200-400 mcg inhaled salbutamol had been given through a spacer to the children whose $\mathrm{FEV}_{1}$ decreased more than $20 \%$ from baseline, or self-reported chest-tightness wheezing, or wheezing by auscultation. Ten minutes after the inhalation of salbutamol, $\mathrm{FEV}_{1}$ recovered to the baseline and the symptoms relieved in all of the children with adverse events. There was no serious adverse event requiring continuous nebulization with bronchodilators and/or corticosteroids.

\section{Discussion}

This study revealed that preschool children who were able to perform spirometry could successfully complete MCh-
BPT, with tolerable and minor adverse events. $\mathrm{PD}_{20} \mathrm{FEV}_{1}$ remains to be an optimal parameter for assessing $\mathrm{BHR}$ with MCh-BPT in preschool children. For children with expiration for less than one second, both $\mathrm{PD}_{20} \mathrm{FEV}_{0.5}$ and $\mathrm{PD}_{20} \mathrm{FEV}_{0.75}$ can be surrogates of $\mathrm{PD}_{20} \mathrm{FEV}_{1}$.

Currently, $\mathrm{PD}_{20} \mathrm{FEV}_{1}$ is extensively recommended as a positive indicator of bronchial provocation tests (including MCh-BPT) in elderly children and adults $(15,16)$. However, some studies have reported that the quality control standards for adults might not be suitable to directly extrapolate to preschool children $(6,17,18)$. The diagnosis of asthma among children aged 5 years or younger has been challenging because of the risks of misdiagnosis. For instance, children without asthma may often experience intermittent respiratory symptoms such as wheezing and cough $(19,20)$. Therefore, ascertainment of the feasibility of spirometry and MCh-BPT for assessment of BHR, and the safety and diagnostic value of MCh-BPT among preschool children may provide valuable insights to clinical management of diseases with BHR (particularly asthma).

We found that the sensitivity and specificity were both $90.0 \%$ and $93.6 \%$ for $\mathrm{PD}_{20} \mathrm{FEV}_{0.5}$ and $\mathrm{PD}_{20} \mathrm{FEV}_{0.75}$, which did not differ significantly from that of $\mathrm{PD}_{20} \mathrm{FEV}_{1}$. However, the sensitivity and the specificity were only $71.9 \%$ and $66.7 \%$ for $\mathrm{PD}_{20} \mathrm{PEF}$, and $77.97 \%$ and $66.67 \%$ for $\mathrm{PD}_{35} \mathrm{MMEF}$. Our findings indicated that in preschool children, for those with an expiratory duration of less than one second, both $\mathrm{PD}_{20} \mathrm{FEV}_{0.5}$ and $\mathrm{PD}_{20} \mathrm{FEV}_{0.75}$, but not $\mathrm{PD}_{20} \mathrm{PEF}$ or $\mathrm{PD}_{35} \mathrm{MMEF}$, could serve as the surrogates for $\mathrm{PD}_{20} \mathrm{FEV}_{1}$ for assessment of BHR. Bentur et al. (21) reported that when $\mathrm{PD}_{20} \mathrm{FEV}_{1}$ was applied as the main parameter for reflecting BHR, it would be more feasible, 
safer, and require less provocative agents to be inhaled than assessment with the symptoms or the breath sounds of wheezing in preschool children. $\mathrm{PD}_{20} \mathrm{FEV}_{1}$ was significantly lower in children with wheezing than in healthy children, whereas $\mathrm{PD}_{20} \mathrm{FEV}_{0.5}$ and $\mathrm{PD}_{20} \mathrm{FEV}_{0.75}$ were comparable between the two groups, indicating that $\mathrm{PD}_{20} \mathrm{FEV}_{1}$ might be preferable to $\mathrm{PD}_{20} \mathrm{FEV}_{0.5}$ and $\mathrm{PD}_{20} \mathrm{FEV}_{0.75}$ for evaluation of BHR in preschool children.

Noteworthily, healthy children who tested positive to MCh-BPT displayed a significantly higher incidence of exposure or sensitive to allergens, frequent upper airway infections, and allergic rhinitis than those with negative results $(\mathrm{P}<0.01)$. It is likely that drugs, food allergens, frequent upper airway infection history, and allergic rhinitis may have contributed to the development of, or exacerbated, BHR. A family history of asthma has been identified as a major risk factor for asthma in children $(22,23)$, whereas asymptomatic BHR may predispose to asthma (24). The mechanisms for the BHR among some of the healthy children warranted further studies.

Methacholine has been the most common provocative agent for BPT in clinical practice. There are international guidelines that offered detailed instructions to perform $\mathrm{MCh}-$ BPT (25). However, the safety of MCh-BPT in preschool children is unclear. We have previously reported that (26) the use of histamine BPT for diagnosing BHR in children aged 11-14 years was safe, with no serious adverse events having been reported. There are also literature reports (27) documenting the use of MCh-BPT in infants and toddlers with tidal breathing method, the results of which showed minor safety concerns. Kivastik et al. (28) have confirmed the safety of MCh-BPT with tidal breathing methods and tripling dose increment, by using air flow blocking technology to measure respiratory resistance in children aged 3 to 6 years old. These pieces of evidence have reaffirmed the safety of MCh-BPT to be applied among preschool children.

Some children developed pharyngeal itching, sore throat, hoarse cough, cough, chest tightness, and mild wheezing. However, all these symptoms were ameliorated through throat gargling, water ingestion, having a rest, or inhalation of salbutamol for $200 \mu \mathrm{g}$ within 10-30 minutes. No serious adverse event was reported, indicating that MCh-BPT in preschool children was safe. The frequency of cough and mild wheezing was significantly higher in children with wheezing than in healthy children. In children with wheezing, the incidence of transient wheezing during $\mathrm{MCh}$ BPT was higher in those with abnormal lung function.

This study assessed BHR in preschool children and confirmed that the methacholine bronchial provocation test was safe and applicable in children aged 4-6 years. Similar with toddlers and adults, some preschool children may have asymptomatic BHR. Whether this would require further medical evaluation or dynamic follow-up merits further investigations. However, some limitations should be considered. First, the sample size and single-center study design might have limited the validity of our conclusion. Moreover, we did not include 3-year-old children, some of whom might also be capable of performing the MCh-BPT.

In summary, although most preschool children in this study can successfully and safely complete MCh-BPT for the diagnosis of BHR in preschool children, however higher success rate was found in larger age groups. $\mathrm{PD}_{20} \mathrm{FEV}_{1}$ remains an optimal indicator of BHR for MCh-BPT, both $\mathrm{PD}_{20} \mathrm{FEV}_{0.5}$ and $\mathrm{PD}_{20} \mathrm{FEV}_{0.75}$ could be surrogate endpoints in preschool children, particularly those with expiration of less than one second. $\mathrm{PD}_{15}$ has a good diagnostic value as $\mathrm{PD}_{20}$ for diagnosing of BHR in preschool children.

\section{Acknowledgments}

Thanks all of the subjects participated in this study. Funding: This study was supported by The National Key Scientific \& Technology Support Program (No. 2015BAI12B10).

\section{Footnote}

Conflicts of Interest: The authors have no conflicts of interest to declare.

Ethical Statement: The authors are accountable for all aspects of the work in ensuring that questions related to the accuracy or integrity of any part of the work are appropriately investigated and resolved. The study protocol was approved by the ethics committee of The First Affiliated Hospital of Guangzhou Medical University, and parents signed informed consent.

\section{References}

1. The Global Strategy for Asthma Management and Prevention. Global Initiative for Asthma (GINA) 2017, accessed on 201801-3. Available online: http://www.ginasthma.org

2. Ding B, DiBonaventura M, Karlsson N, et al. A cross-sectional assessment of the prevalence and burden of mild asthma in urban China using the 2010, 2012, and 2013 China National 
Health and Wellness Surveys. J Asthma 2017;54:632-43.

3. Wang HY, Zheng JP, Zhong NS. Time trends in the prevalence of asthma and allergic diseases over 7 years among adolescents in Guangzhou city. National Medical Journal of China 2006;86:1014-20.

4. National survey of the prevalence of asthma in 900,000 children aged 0-14 years. Chinese Journal of Tuberculosis and Respiratory Diseases 1993;16:64-8.

5. Chen YZ. Assessment of the prevalence of asthma among children in urban China. Chinese Journal of Pediatrics 2003;41:123-7.

6. Sha L, Zhao MJ, Liu CH, et al. The prevalence of asthma in children: a comparison between the year of 2010 and 2000 in urban China. Chinese Journal of Tuberculosis and Respiratory Diseases 2015,38:664-8.

7. Beydon N, Davis SD, Lombardi E, et al. An Official American Thoracic Society/European Respiratory Society Statement: Pulmonary Function Testing in Preschool Children. Am J Respir Crit Care Med 2007;175:1304-45.

8. Cockcroft DW. Direct challenge tests. Airway hyperresponsiveness in asthma: its measurement and clinical significance. Chest 2010;138:18S-24S.

9. Martinez FD, Wright AL, Taussig LM, et al. Group Health Medical Associates. Asthma and wheezing in the first six years of life. N Engl J Med 1995;332:133-8.

10. Department of Maternal and Child Health and Community Health, Ministry of Health. The growth and development of children under the age of 7 years. Chinese Journal of Reproductive Health 2009;20:9.

11. The Subspecialty Group of Respiratory Diseases, The Society of Pediatrics, Chinese Medical Association, The Editorial Board, Chinese Journal of Pediatrics. Guideline for the diagnosis and optimal management of asthma in children. Chinese Journal of Pediatrics 2016;54:167-81.

12. Zhang QL, Zheng JP, Yuan BT, et al. Feasibility and predicted equations of spirometry in Shenzhen preschool children. Chinese Journal of Pediatrics 2005;43:843-8.

13. The Subspecialty Group of Pulmonary Function Testing, Chinese Medical Association. Guidelines of pulmonary function (Part III): histamine and methacholine bronchial provocation test. Chinese Journal of Tuberculosis and Respiratory Diseases 2014;37:566-71.

14. Zhong NS, Chen RC, Ou-yang M, et al. Bronchial hyperresponsiveness in young students of southern China: relation to respiratory symptoms, diagnosed asthma, and risk factors. Thorax 1990;45:860-5.

15. Yu X, Zhu H, Yang X, et al. Study on dynamic changes of airway hyperresponsiveness in children with cough variant asthma. Zhonghua Yi Xue Za Zhi 2014;94:1215-8.

16. The Subspecialty Group of Respiratory Diseases, The Society of Pediatrics, Chinese Medical Association. Series guidelines of pulmonary function for Children: bronchial provocation test. Journal of Applied Clinical Pediatrics 2017;32:263-9.

17. Brand PL, Caudri D, Eber E, et al. Classification and pharmacological treatment of preschool wheezing: changes since 2008. Eur Respir J 2014,43:1172-7.

18. Ducharme FM, Tse SM, Chauhan B. Diagnosis, management, and prognosis of preschool wheeze. Lancet 2014;383:1593-604.

19. Doherty G, Bush A. Diagnosing respiratory problems in young children. Practitioner 2007;251:20-5.

20. Pedersen S. Preschool asthma--not so easy to diagnose. Prim Care Respir J 2007;16:4-6.

21. Bentur L, Beck R, Elias N, et al. Methacholine bronchial provocation measured by spirometry versus wheeze detection in preschool children. BMC Pediatrics 2005;5:19.

22. Li WZ, Li ZQ, Zhong JY, et al. Determination of the airway reactivity in asthmatic children in the remission stage. Chinese Journal of Contemporary Pediatrics 2000;3:200-1.

23. WHO/NHLBI Workshop Report. National heart, lung, and blood institute. Pocket guide for asthma management and prevention in children5 years and younger 2009 . Available online: http://www.ginasthma.org.

24. Zhong NS, Chen RC, Yang MO, et al. Is asymptomatic bronchial hyperresponsiveness an indication of potential asthma? A two-year follow-up of young students with bronchial hyperresponsiveness. Chest 1992;102:1104-9.

25. Aurora P, Stocks J, Oliver C, et al. Quality control for spirometry in preschool children with and without lung disease. Am J Respir Crit Care Med 2004,169:1152-9.

26. Zheng JP, Chen RC, Zhong NS, et al. Measurement of airway hyperresponsiveness in elder children. National Journal of Pediatrics 1994;32:153-5.

27. Yuan HX, Huang Y, Luo J, et al. Safety of methacholine in bronchial provocation test for infants. Chinese Journal of New Drugs And Clinical Remedies 2007;26:222-5.

28. Kivastik J, Gibson AM, Primhak RA. Feasibility of shortened methacholine challenge in preschool children. Pediatr Pulmonol 2006;41:146-50.

Cite this article as: $\mathrm{Li} \mathrm{BH}$, Guan WJ, Zhu Z, Gao Y, An JY, Yu XX, Zheng JP. Methacholine bronchial provocation test for assessment of bronchial hyperresponsiveness in preschool children. J Thorac Dis 2019;11(10):4328-4336. doi: 10.21037/ jtd.2019.09.47 


\section{Supplementary}

Table S1 Work flow of MCh-BPT

\begin{tabular}{|c|c|c|c|c|c|}
\hline Steps & \multicolumn{2}{|c|}{ Regular (doubling dose increase) } & \multicolumn{2}{|c|}{ Simplified (quadrupling dose increase) } & $\begin{array}{l}\text { Cumulative dose } \\
\qquad(\mu \mathrm{mol})\end{array}$ \\
\hline 1 & 0.30 & 1 & - & - & 0.05 \\
\hline 2 & 0.30 & 1 & 0.60 & 1 & 0.1 \\
\hline 3 & 0.60 & 1 & - & - & 0.2 \\
\hline 5 & 2.50 & 1 & - & - & 0.8 \\
\hline 6 & 2.50 & 2 & 2.50 & 3 & 1.6 \\
\hline 7 & 2.50 & 4 & - & - & 3.2 \\
\hline 8 & 5.00 & 4 & 5.00 & 6 & 6.4 \\
\hline
\end{tabular}

MCh inhalation with Yan's method with 4-fold dose increase for healthy subjects and during the provocation test if FEV ${ }_{1}$ decrease less than $10 \%$, quadrupling dose increase was used, if $\mathrm{FEV}_{1}$ decrease $>10 \%$ but $<20 \%$, then doubling dose increase was applied. Mch-BPT, methacholine bronchial provocation test. $\mathrm{FEV}_{1}$, forced expiratory volumes in one second.

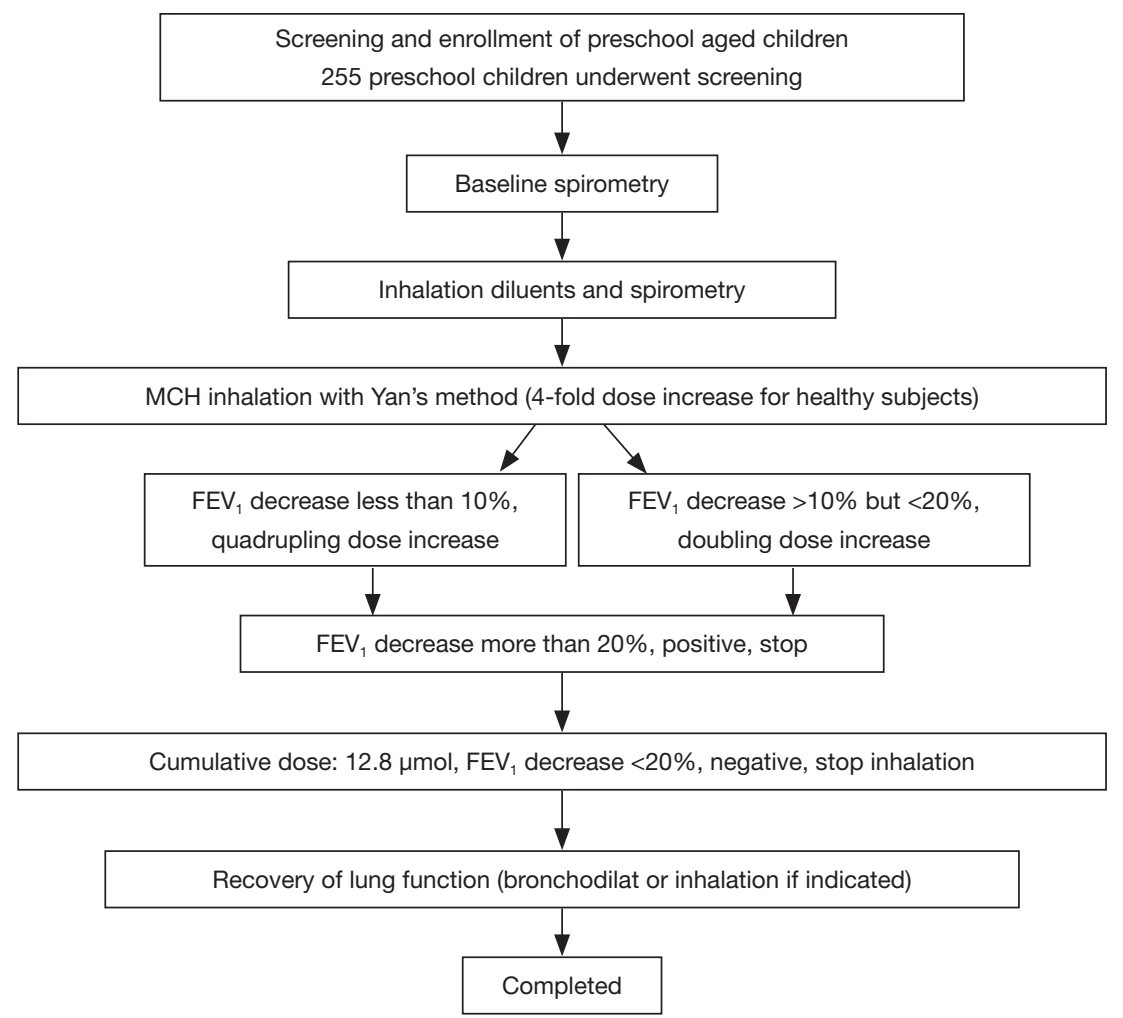

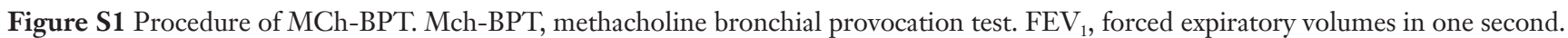

